\title{
Pengembangan Diri Anak Berkebutuhan Khusus Melalui Pendekatan Konseling Multikultural
}

\author{
Heny Kristiana Rahmawati \\ Fakultas Dakwah dan Komunikasi Islam, IAIN Kudus \\ Email: henykr13@gmail.com
}

\begin{abstract}
Abstrak
Penanganan anak berkebutuhan khusus, memerlukan keberpihakan kultural dan struktural dari berbagai pihak baik orangtua, masyarakat dan pemerintah. Penelitian ini menggunakan pendekatan deskriptif kualitatif studi kasus. Pelaksanaan Konseling Multikultural yang diterapkan selain pendampingan sehari-hari adalah hydrotherapy, massage dan acupreseur, outing class, peringatan hari-hari penting, senam sehat setiap pagi, permainan, panggung gembira dan lain-lain.
\end{abstract}

Kata Kunci: pengembangan diri, anak berkebutuhan khusus, konseling multicultural

\begin{abstract}
Handling children with special needs requires cultural and structural alignments from various parties, both parents, community and government. This research uses a descriptive qualitative case study approach. The implementation of Multicultural Counseling that is applied in addition to daily assistance is hydrotherapy, massage and acupressure, outing classes, commemoration of important days, healthy exercise every morning, games, happy stages and others.
\end{abstract}

Keywords: self-development, the child with special needed, multicultural counseling

\section{PENDAHULUAN}

Anak berkebutuhan khusus sering kali mengalami berbagai persoalan psikologis yang timbul akibat kelainan bawaan dirinya maupun akibat respons lingkungan terhadap ketunaan yang dialami anak tersebut.Dukungan dari lingkungan social (dukungan social) bagi anak berkebutuhan khusus sangat mempengaruhi perkembangan anak tersebut (Efendi, 2008). Dalam kenyataannya, anak berkebutuhan khusus yang memperoleh dukungan social yang baik dari lingkungannya mampu menunjukkan prestasi tak kalah gemilang baik dalam bidang pendidikan formal maupun ketrampilan sehingga anak tersebut mampu mandiri dalam kehidupannya (Walinono, 1999)

Anak berkebutuhan khusus merupakan bagian dari masyarakat yang harus dibebaskan dan diberdayakan baik dari keterbatasan fisik maupun mentalnya. Upaya tersebut dilakukan dengan cara memberikan hak yang sama dalam bidang pendidikan secara berkesinambungan, terpadu dan penuh tanggung jawab agar mereka tidak lagi dianggap sebagai warga kelas dua yang hanya dipandang sebelah mata oleh sebagian orang. Penyandang cacat, mereka memiliki keterbatasan fisik, sehingga mereka akan memiliki sedikit kesulitan dalam menyesuaikan. Hambatan tersebut diperburuk oleh situasi lingkungan dan fasilitas umum yang tidak kondusif untuk pertumbuhan, partisipasi dan aktivitas dalam kehidupan (Noor, 2017). 
Penanganan anak berkebutuhan khusus, memerlukan keberpihakan kultural dan struktural dari berbagai pihak baik orangtua, masyarakat dan pemerintah. Hal ini karena masih adanya pemahaman yang keliru dan sikap diskriminatif terhadap anak berkebutuhan khusus di lingkungan keluarga dan masyarakat, baik dalam bentuk verbal maupun non verbal. Selain itu anak berkebutuhan khusus rentan mendapatkan kekerasan dan perlakuan salah. Dalam menangani anak-anak berkebutuhan khusus, para pendamping memerlukan pengetahuan tentang anak-anak tersebut, keterampilan mengasuh dan melayaninya. Anak berkebutuhan khusus perlu mendapat dorongan, tuntunan, dan praktek langsung secara bertahap. Potensi yang dimiliki anakanak berkebutuhan khusus akan tumbuh berkembang seiring dengan keberhasilan peran pendamping dalam memahami dan memupuk potensi anak-anak tersebut (Kementerian Pemberdayaan Perempuan dan Perlindungan Anak Republik Indonesia, 2013, hal.03).

Konseling multikultural sangatlah penting kehadirannya, terutama individu yang membutuhkan bantuan untuk menyelesaikan masalah maupun untuk pengembangan diri. Memang pada prakteknya tidak semua individu itu mampu menyelesaikan masalah sendiri dan mengetahui potensi diri dan tidak tahu untuk pengembangannya, sehingga individu tidak bisa tumbuh dan berkembang secara optimal. Untuk bisa menyelesaikan masalah dan membangun pemenuhan kebutuhan diri, setiap individu ada yang bisa menyelesaikan sendiri, tapi ada juga membutuhkan bantuan pihak lain. Di sinilah konseling multikultural menemui relevansinya.

\section{METODOLOGI PENELITIAN}

Pendekatan yang dilakukan dalam penelitian ini adalah dengan pendekatan deskriptif kualitatif serta metode penelitian yang digunakan adalah dengan menggunakan metode studi kasus. Untuk mengetahui pola pelaksanaan pendekatan konseling multikultural anak berkebutuhan khusus agar mampu mengembangkan diri secara optimal. Teknik pengumpulan data dalam penelitian ini adalah dengan wawancara, observasi, dokumentasi dan catatan lapangan.

\section{HASIL PENELITIAN DAN PEMBAHASAN}

Dalam penelitian ini, peneliti melakukan observasi langsung di Rumah Terapi Anak Berkebutuhan Khusus Darul Fathonah. Rumah Terapi Anak Berkebutuhan Khusus Darul Fathonah berlokasi di daerah Kudus Kota tepatnya di jalan KH. Arwani, Pejaten, kecamatan Krandon Kabupaten Kudus, Jawa Tengah. Berada di tengahtengah daerah pemukiman warga sehingga akses untuk menjangkau ke lokasi Rumah Terapi Anak Berkebutuhan Khusus Darul Fathonah cukup mudah.

Disampaikan oleh Ibu Hajar selaku sekretaris dan juga terapis Rumah Terapi Anak Berkebutuhan Khusus Darul Fathonah, bahwa anak-anak berkebutuhan khusus yang berada di Rumah Terapi Anak Berkebutuhan Khusus Darul Fathonah adalah anak-anak yang mayoritas tidak diterima di sekolah Inklusi maupun Sekolah Luar Biasa. Hal itu dikarenakan anak-anak tersebut masuk ke kategori Tunaganda yang biasanya perlu pendampingan lebih intens dan waktu tambahan setiap harinya.

Tunaganda merupakan anak yang memiliki kombinasi kelainan dua atau lebih jenis diagnosis dalam individu, sehingga dia tidak hanya dapat diatasi dengan suatu program pendidikan khusus untuk satu kelainan melainkan harus didekati dengan variasi program pendidikan sesuai kelainan yang dimiliki. Selain itu, anakanak yang ada di Rumah Terapi Anak Berkebutuhan Khusus Darul Fathonah biasanya belum siap jika harus 
masuk di Sekolah Luar Biasa, sehingga untuk mempersiapkan diri terlebih dahulu para orang tua memilih untuk memasukkan anak-anak mereka ke Rumah Terapi Anak Berkebutuhan Khusus Darul Fathonah.

Ibu Heni selaku ketua Rumah Terapi Anak Berkebutuhan Khusus Darul Fathonah menyampaikan, Rumah Terapi berawal dari keprihatinan saat bertemu dengan seorang anak dengan gangguan autis yang dipasung oleh neneknya sedangkan kedua orang tua anak tersebut sudah meninggal. Karena kejadian tersebut, para relawan peduli mencoba mencarikan tempat untuk anak tersebut dapat didampingi di tempat yang aman, namun tidak ditemukan tempat yang mau menerima secara gratis. Karena anak tersebut tidak ada lagi yang dapat membiayai. Keprihatinan bertambah, yang akhirnya membuat para relawan peduli berfikir bahwa keterbatasan soal ekonomi pasti juga dialami oleh keluarga yang memiliki anak berkebutuhan khusus lainnya.

Rumah Terapi Anak Berkebutuhan Khusus Darul Fathonah mulai berdiri sekitar tahun 2016 dari dukungan para psikolog yang ikhlas dalam mendampingi tanpa ada biaya. Lembaga swadaya ini juga didukung oleh salah satu psikolog senior dari Rumah Sakit Umum Daerah Kudus yang kemudian berperan sebagai konsultan sekaligus membantu dalam diagnosis kategori anak berkebutuhan khusus di Rumah Terapi Anak Berkebutuhan Khusus Darul Fathonah.

Dalam pelaksanaan pendampingan, Rumah Terapi Anak Berkebutuhan Khusus Darul Fathonah memiliki terapis dengan latar belakang keilmuan psikologi, konseling, kesehatan dan lain-lain. Jenis pendekatan pendampingan yang dilakukan disesuaikan dengan kebutuhan anak saat diagnosis awal masuk. Diagnosis langsung menggunakan tes psikologi dibantu dengan surat keterangan resmi dari Rumah Sakit Umum Daerah Kudus. Saat sudah mengetahui hasil dari diagnosis, maka para terapis akan menentukan pendekatan yang dilakukan. Untuk saat ini anak-anak berkebutuhan khusus dan pendekatan pendampingan konselingnya secara umum adalah :

1. Autism : Applie Behaviour Analysis (ABA)

Autism adalah kelainan perkembangan otak anak yang menyebabkan gangguan dalam interaksi sosial, gangguan focus, hingga gangguan kemampuan bahasa dan komunikasi. Tingkat keparahan bervariasi. Menggunakan pendekatan terapi ABA yang merupakan program terapi terstruktur yang berfokus mengajarkan seperangkat keterampilan khusus. Terapi ini mengajarkan anak autism untuk memahami dan mengikuti intruksi verbal, merespon perkataan orang lain, mendeskripsikan sebuah benda, meniru ucapan dan gerakan orang lain, hingga mengajarkan baca tulis (Andipurnama, 2015). Pendampingan di Rumah Terapi Anak Berkebutuhan Khusus Darul Fathonah menggunakan ABA untuk anak autism variasi sedang meliputi, belajar focus kontak mata, belajar berdiri sendiri, belajar duduk sendiri, belajar memegang benda, belajar mengambil benda, belajar berdiam diri, menyebutkan nama saat ditanya, konsentrasi, mengontrol emosi, melakukan perintah. Untuk autis dengan variasi berat misalnya belajar menggerakkan tubuh, dikenalkan dengan bendabenda sekitar, mengontrol emosi, latihan memegang benda, menyusun lego.

2. Down syndrome : Okupasi Terapi

Down syndrome merupakan suatu kondisi genetik yang menghasilkan beberapa tingkat ketidakmampuan belajar dan berbagai karakteristik fitur fisik (Khusus, 2019). Sebagian penderita dapat mengalami kelainan yang ringan, tetapi sebagian lainnya dapat mengalami gangguan yang berat hingga menimbulkan penyakit jantung (Rohmadheny, 2016). Bentuk pendekatan pendampingan yang dilakukan salah satunya adalah melalui okupasi terapi. Dalam praktiknya okupasi terapi menggunakan okupasi atau aktivitas terapeutik dengan tujuan 
mempertahankan atau meningkatkan komponen kinerja okupasional (senso-motorik, pesepsi, kognitif, sosial dan spiritual) dan area kinerja okupasional (perawatan diri, produktivitas dan pemanfaatan waktu luang) sehingga pasien atau klien mampu meningkatkan kemandirian fungsional, meningkatkan derajat kesehatan dan partisipasi di masyarakat sesuai perannya (kep). Dalam pelaksanaannya di Rumah Terapi Anak Berkebutuhan Khusus Darul Fathonah salah satunya kegiatan rutin senam setiap pagi sebelum pembelajaran dimulai. Hal ini dilakukan manfaatnya untuk melatih gerak motorik dan belajar respon ramai. Selain itu dalam sehari-hari diajarkan tentang latihan berbicara, mengarahkan fokus misalnya meronce benang, memasukkan koin ke lubang celengan.

3. Tunarungu : terapi wicara

Tunarungu merupakan anak yang mengalami gangguan pada organ pendengarannya sehingga mengakibatkan ketidakmampuan mendengar, mulai dari tingkatan yang ringan sampai yang berat sekali yang diklasifikasikan kedalam tuli (deaf) dan kurang dengar (hard of hearing) (Hernawati, 2007). Beberapa pendekatan pendampingan yang dilakukan dalam pembelanjaran sehari-hari adalah belajar mengenal alphabet, belajar mengenal benda, menulis, membaca, perkataan yang ditulis, memperjelas gerakan mulut saat berbicara, perlakuan hampir sama dengan anak normal hanya ada beberapa pendampingan khusus.

4. Speech Delay : terapi wicara

Perkembangan bicara yang terlambat biasanya disertai dengan perkembangan sensorikmotorik, perseptual motoric yang terlambat pula. Karena bicara dan berbahasa berhubungan erat dengan system motoric, yang diatur oleh system syaraf pusat. Sistem syaraf pusat (Central Nervous System) mengatur perkembangan system sensorik, Sensorik-motorik, persepsi motorik dan kognisi. Pada usia dini anak yang mengalami gangguan keterlambatan bicara harus dengan cepat diberikan intervensi berupa kegiatan terapi sebagai usaha preventif alam masa tumbuh kembangnya (Fitriyani, 2018). Dalam pendampingannya bisa diajarkan dengan melatih gerak saraf lidah, melipat, menjulur. Selain itu juga diajarkan kosakata dasar A, I, U, E, O dan kata mudah seharihari dengan berulang.

5. Cerebral Palsy

Cerebral palsy dianggap sebagai salah satu disabilitas yang cukup berat pada masa anak-anak dan memiliki dampak yang cukup besar pada keluarga dan semua anak dalam keluarga tersebut. Kondisi cerebral palsy membutuhkan pelayanan kesehatan yang serius, begitu pula masalah pendidikan dan pelayanan sosialnya (Valentina, 2014). Dalam pendampingan sehari-hari yang dilakukan misalnya, belajar fokus, latihan motoric, latihan berjalan, mengenggam atau mengambil barang, tos tangan kanan kiri bergantian, mengenal nama barang.

6. Retardasi Mental : cognitive and behavior therapy (CBT)

Anak tuna grahita atau disebut juga retardasi mental (RM) mempunyai fungsi intelektual dibawah rata - rata (70) yang muncul bersamaan dengan kurangnya perilaku adaptif, ketidakmampuan beradaptasi dengan kehidupan sosial sesuai tingkat perkembangan dan budaya (Wardhani). Salah satu cara pendampingannya bisa menggunakan pendekatan cognitive behavior therapy (CBT) merupakan psikoterapi yang berfokus pada kognisi yang dapat berkurang minimal setengah dimodifikasi secara langsung, yaitu ketika individu mengubah pikiran maladaptifnya (maladaptive thought) maka secara tidak langsung juga mengubah tingkah lakunya yang tampak (overt action) (Elna Yuslaini Siregar, Juni 2013). Bentuk pendampingan sehari-hari misalnya fokus dalam belajar, mengenalkan orang-orang terdekat, kontrol diri.

7. Disleksia

Disleksia merupakan suatu gangguan yang berpusat pada sistem saraf, dan dengannya mengalami kesulitan dalam hal membaca, menulis, mengeja, atau dapat dikatakan kesulitan dalam mengenali huruf-huruf 
(Anggrayani). Oleh karena disleksia merupakan salah satu hambatan belajar yang biasanya terdeteksi dari hasil kemampuan anak dalam membaca. Pendampingannya dengan mengenalkan huruf-huruf yang hampir sama bentuknya seperti B dengan $D$, huruf I dengan J, selain itu dengan mengucapkan setiap kata dengan jelas dan pelan, membuat serangkaian cerita yang menarik minat anak untuk mendengarkan terkait huruf-huruf, memberikan gambaran tentang bentuk suatu huruf missal huruf $\mathrm{O}$ seperti bola dan sebagainya.

Pendekatan yang tepat dan sesuai melalui konseling multikultural memang perlu untuk dilakukan. Karena setiap anak selalu memiliki tingkat potensinya masing-masing. Di Rumah Terapi Anak Berkebutuhan Khusus Darul Fathonah, anak berkebutuhan khusus diidentifikasi secara mendetail dan dibedakan setiap variasi spesialnya. Sehingga apabila dilihat secara rinci, walaupun sama-sama menderita tunarungu atau autism namun untuk pendekatan yang dilakukan bisa jadi berbeda. Karena melihat dari faktor tingkatan kekhususannya atau potensi yang dimiliki.

Banyak agenda kegiatan yang dilaksanakan selain pendampingan sehari-hari oleh terapis di Rumah Terapi Anak Berkebutuhan Khusus Darul Fathonah. Misalnya, setiap satu atau dua bulan sekali Rumah Terapi melaksanakan hydrotherapy yang manfaatnya untuk membangun otot, membantu pengembangan keterampilan motorik, mendorong konsentrasi, control dan koordinasi, serta memungkinkan untuk kebebasan yang jauh lebih besar dari gerakan. Selain itu juga terdapat massage dan acupreseur yang dapat melatih stimulasi hormonal dan otot. Kemudian tentu saja banyak kegiatan-kegiatan lain seperti outing class, peringatan hari-hari penting, senam sehat setiap pagi, permainan, panggung gembira dan lain-lain yang merupakan upaya agar anak berkebutuhan khusus mampu untuk mengembangkan diri sesuai dengan kebutuhannya sehingga memiliki potensi diri yang optimal.

\section{SIMPULAN}

Berdasarkan penelitian yang telah dilakukan di Rumah Terapi Anak Berkebutuhan Khusus Darul Fathonah mengenai pengembangan diri anak berkebutuhan khusus melalui pendekatan konseling multikultural, dapat diperoleh bahwa setiap anak berbeda jenis dan variasi berkebutuhan khususnya maka berbeda pula dalam penanganannya. Pendampingan yang dilakukan lebih menekankan pada pendampingan intensif dengan melihat gejala-gejala, karakteristik serta latar belakang dari setiap anak. Dengan adanya penelitian dan pemaparan kegiatan pendampingan pengembangan diri anak berkebutuhan khusus di Rumah Terapi Anak Berkebutuhan Khusus Darul Fathonah, diharapkan pola pendekatan konseling multikultural juga mampu diterapkan di lembaga-lembaga pemerintah seperti sekolah luar biasa dan sekolah inklusi. Selain itu, dengan semakin berkembangnya kegiatan pengembangan diri untuk anak berkebutuhan khusus orang tua atau keluarga yang memiliki anak berkebutuhan khusus tidak perlu lagi malu atau mengucilkan karena mereka juga mempunyai hak kesempatan yang sama dengan anak normal lainnya. Setelahnya semoga masyarakat dan lingkungan juga semakin mampu untuk menyediakan sarana prasarana serta fasilitas yang ramah untuk anak berkebutuhan khusus dan memberikan kesempatan yang sama saat mereka kembali ke masyarakat.

\section{DAFTAR PUSTAKA}

Abdul Mujib, Kepribadian Dalam Psikologi Islam, Jakarta : PT Raja Grafindo Persada, 2006.

Marmawi, Persamaan Gender dalam Pengembangan Diri, Jurnal Visi Pendidikan.

Tarsis Tarmudji, Pengembangan Diri, Yogyakarta: Liberty Yogyakarta, 1998. 
Bregita Rindy Antika, dkk. Studi Pengembangan Diri (Bakat Minat) Pada Siswa Komunitas Sastra di Sekolah Alternatif Qoryah Toyyibah Salatiga, Indonesia Journal of Guidance and Counseling: Theory and Application 2 (3) (2013).

Heny Kristiana Rahmawati, Kegiatan Pengembangan Diri Dalam Menggali Potensi Anak Tunanetra Di Panti Tunanetra Aisyiyah Ponorogo, Konseling Edukasi: Journal of Guidance and Counseling, Vol. 2, No. 1, Januari-Juni 2018.

Kristiawan P.A Nugroho, dkk. Gaya Hidup Yang Memengaruhi Kesehatan Anak Berkebutuhan Khusus Di Slb Negeri Salatiga. Jurnal Keperawatan Muhammadiyah 2(2) 2017.

Nandiyah Abdullah, Mengenal Anak Berkebutuhan Khusus, Magistra No. 86 Th. XXV Desember 2013.

Muraeni Mursanib, Meningkatkan Keterampilan Identifikasi Anak Berkebutuhan Khusus.... Tri Sentra Jurnal Ilmu Pendidikan Vol.2 Edisi 4 Juli-Desember 2013.

Fatma Laili Khoirun Nida, membangun konsep diri bagi Anak berkebutuhan khusus, jurnal thufula, Vol. 2 | No. 1 | Januari-Juni 2014.

Brown. J. D, Understunding Research In Second Language Learning, New York: Crambridge University Press, 1988.

Supriatna, M. (n.d.). Bimbingan dan Konseling Lintas Budaya. 103.23.244.11. Retrieved from http://103.23.244.11/Direktori/FIP/JUR._psikologi_pend_dan_bimbingan/1960082919870 31mamat_supriatna/24._bk_lintas_budaya_Revisi_Final_.pdf.

Indrawaty, S. A., \& Ed, D. (2014). Kompetensi pemahaman konselor terhadap pandangan hidup konseli yang berbeda budaya.

Miskanik, penggunaan konseling multikultural dalam mendorong perkembangan kepribadian anak berkebutuhan khusus (abk), http://journal.Ippmunindra.ac.id/index.php/sosio ekons, Volume 10, No. 3, Desember 2018.

Corey.1997. Theory and Practice of Group Counseling. California. Brooks/Cole Publishing Compani.

Samuel t gladding, Konseling Profesi yang Menyeluruh, Jakarta: indeks, 2012.

Nuzliah, Conseling Multikultural, Jurnal Edukasi vol 2, nomor 2, july 2016.

Prasetyo, Tri. 2008. Ilmu Budaya Dasar (MKDU), Cet. Ke-2. Jakarta: Rineka Cipta.

Dirham Gumawang Andipurnama, file.upi.edu.Direktori.FIP.deteksi_dini dan penanganan pada autistik.

Pusat Studi Individu Berkebutuhan Khusus, Down Syndrome-Yuk Kenali Lebih Dalam, https://www.usd.ac.id/pusat/psibk/2019/03/21/down-syndrome/

Prima Suci Rohmadheny, Studi Kasus Anak Downsyndrome Case Study Of Down Syndrome Child, Jurnal CARE Edisi Khusus Temu IImiah (Vol. 03 No.3 Maret 2016) 69.

Keputusan-menteri-kesehatan-no-571-tentang-standar-profesi-okupasi-terapis.pdf.

Tati Hernawati, Pengembangan Kemampuan Berbahasa dan Berbicara Anak Tunarungu, JASSI_anakku Volume 7 Nomor 1 Juni 2007.

Fitriyani dkk, Gambaran Perkembangan Berbahasa Pada Anak Dengan Keterlambatan Bicara (Speech Delay) : Study Kasus Pada Anak Usia 9 Tahun Kelas 3 Sd Di Sds Bangun Mandiri, Universitas Negeri Jakarta : Prosiding Seminar dan Diskusi Nasional Pendidikan Dasar 2018.

Tience Debora Valentina, Penyesuaian Psikologis Orangtua Dengan Anak Cerebral Palsy, Psikologia, 2014, Vol. 9, No. 2.

Sintia Hartika Wardhani, Play Theraphy : Cooperative Play With Puzzle Increase Socialization Skill in Children With Mental Retardation, https://e-journal.unair.ac.id > PNJ > article.

Elna Yuslaini Siregar, Rodiatul Hasanah Siregar, Penerapan Cognitive Behavior Therapy (CBT) Terhadap Pengurangan Durasi Bermain Games Pada Individu Yang Mengalami Games Addiction, Jurnal Psikologi, Volume 9 Nomor 1, Juni 2013.

Madinatul Munawaroh dan Novi Trisna Anggrayani, Prosiding, Mengenali TandaTanda Disleksia pada Anak Usia Dini. Universitas PGRI Yogyakarta. 